\title{
As religiões afro-brasileiras na escola
}

\section{The Afro-Brazilian religions in school}

\author{
Guilherme Paiva de Carvalho \\ Eliane Anselmo da Silva \\ Universidade do Estado do Rio Grande do Norte (UERN), Brasil
}

\section{Resumo}

O artigo aborda as representações de professores/as da educação básica sobre as religiões afro-brasileiras. Para tanto, o estudo utiliza um método qualitativo baseado na técnica de entrevista semiestruturada e na análise de conteúdo. A concepção de representação, formulada por teorias que compõem os estudos culturais, é uma referência para a análise da visão dos/as professores/as sobre as religiões afro-brasileiras. No sistema educacional brasileiro, as culturas africanas e afro-brasileiras tornaram-se conteúdos obrigatórios na educação básica com a Lei 10.639/2003, incorporada pela Lei 11.645/2008. Com o racismo simbólico constituído na história da sociedade brasileira, são construídas formas estereotipadas de representação e estigmas sobre as religiões afro-brasileiras. Os resultados da pesquisa mostram que formas estereotipadas de representação podem ser observadas na perspectiva de profissionais da educação básica que não tiveram contato com conhecimentos sobre as culturas africanas e afro-brasileiras. Por outro lado, cursos de formação continuada proporcionam uma visão mais abrangente sobre as religiões de matriz africana e formas incipientes de ruptura epistemológica na educação brasileira.

Palavras-chave: cultura afro-brasileira; representação; educação; religião.

\section{Abstract}

The article approaches the representations of teachers that work in basic education, about the Afro-Brazilian religions. In order to do so, the study utilizes a qualitative method based on technical semi-structured interviews and in the analysis of the content. The conception of representation, formulated by theories that compose the culture studies, is a reference for the analysis of the vision of teachers about the Afro-Brazilian religions. For the culture studies, the representation connects meaning, language and culture. In the Brazilian educational system, the African and Afro-Brazilian cultures became obligatory in contents of basic education with the Law 10.639/2003, incorporated for the Law 11.645/2008. With the symbolic racism constituted in the history of Brazilian society are constructed stereotypical forms of representation and stigmas about the Afro-Brazilian religions. These stereotypical forms of representation can be observed in the perspectives of professionals of basic education that didn't have contact with knowledges about the African and Afro-Brazilian cultures. On the other side, the courses of continued formation propitiate a vision more comprehensive about the Afro-Brazilian religions and incipient forms of epistemological rupture in Brazilian education.

Keywords: Afro-Brazilian Culture; Representation; Education; Religion. 


\section{INTRODUÇÃO}

A investigação aborda o tema das religiões de matriz africana no espaço escolar, levando em consideração a problemática das relações étnico-raciais no âmbito do sistema educacional brasileiro e os impactos de programas de formação continuada de professores/as na educação básica, na modalidade de Educação a Distância (EAD). Assim, o estudo propõe analisar as representações de profissionais do magistério da educação básica da rede pública de ensino sobre as religiões afro-brasileiras.

Na sociedade brasileira, as desigualdades de gênero, classe, "raça" e etnia originaram-se de uma cultura influenciada por uma visão eurocêntrica correspondente à dimensão simbólica e a relaç̃ões complexas de poder. Tendo uma sociedade constituída pela pluralidade étnica, o Estado brasileiro forjou a construção de uma identidade nacional baseada em uma perspectiva monocultural e no mito da democracia racial. Até praticamente o final do século XX, a temática da diversidade cultural e étnica foi desconsiderada pelo sistema educacional, mesmo considerando o caráter multicultural da sociedade brasileira (Candau, 2008).

A definição de papéis sociais subalternos para homens e mulheres miscigenados/as, afro-brasileiros/as e indígenas, articulada a esta estrutura se reflete na estratificação social e na reprodução de desigualdades de gênero, classe e etnia. De acordo com Azevedo (2000), o sistema educacional no Brasil instituiu uma estrutura caracterizada pela estratificação social e a desigualdade econômica.

No Brasil, é somente com a Constituição Federal de 1988 que teve início um processo de reconhecimento, por parte do Estado, dos direitos de grupos sociais afro-brasileiros e populações indígenas preservarem a sua cultura e as suas tradições. No final do século XX e início do XXI, as políticas educacionais passaram a enfatizar o caráter multicultural e a diversidade étnica da sociedade. Com isto, há um reconhecimento, no âmbito normativo, das contribuições das culturas indígenas e afro-brasileiras para a formação cultural do país.

Durante os governos Fernando Henrique Cardoso (FHC) e Lula, são criadas políticas educacionais que destacam a relevância da compreensão da diversidade cultural para a formação de uma consciência cidadã, como é o caso dos Parâmetros Curriculares Nacionais (PCN's) de 1997, a Lei 10.639/2003, incorporada pela Lei 11.645/2008, além das Diretrizes Curriculares Nacionais para a Educação das Relações ÉtnicoRaciais, que enfatiza o estudo das culturas africanas e afro-brasileiras em todos os níveis de ensino, as Diretrizes para Educação Escolar Indígena e Educação Escolar Quilombola (Carvalho; Silva, 2015). 
Considerando esses aspectos, propôs-se na pesquisa analisar o modo como profissionais do magistério da educação básica, que lecionam em cidades próximas a comunidades quilombolas da região Oeste do Rio Grande do Norte, além de professores/as que concluíram cursos de formação continuada que abordaram a temática das relações étnico-raciais, representam as religiões afro-brasileiras. Os resultados da pesquisa oferecem subsídios para refletir sobre a relevância do espaço escolar para a compreensão da diversidade cultural, no combate ao racismo e a formas de discriminação, bem como na promoção da igualdade no que concerne às relações étnico-raciais.

Nesta perspectiva, políticas educacionais e programas de formação continuada de educadores/as, implantados no Brasil durante o final do século XX e a primeira década do século XXI, têm como finalidade proporcionar o reconhecimento da diversidade cultural na instituição escolar. É importante verificar os impactos de tais programas no sentido da inclusão da temática referente às relações étnico-raciais na educação de meninas e meninos, possibilitando uma reflexão crítica sobre a diversidade cultural que caracteriza o país.

Para a realização da pesquisa foram entrevistados/as 30 (trinta) professores/as que lecionam na educação básica da rede pública de ensino do Rio Grande do Norte (RN), no período de agosto a setembro de 2014 e maio a junho de 2015, sendo 15 (quinze) profissionais que lecionam em cidades próximas a comunidades quilombolas, nos municípios de Portalegre (RN), Patu (RN), Assu (RN) e Ipanguaçu (RN); e 15 (quinze) que concluíram o curso de formação continuada "Educação para as Relações Étnico-Raciais", ofertado na modalidade de EAD pela Universidade Federal do Rio Grande do Norte (UFRN), nas cidades de Encanto (RN), Martins (RN), Felipe Guerra (RN), Nísia Floresta (RN), Serra Caiada (RN), Riacho da Cruz (RN) e Lucrécia (RN). Assim, a pesquisa propõe comparar a visão de profissionais do magistério que não realizaram cursos de formação continuada e lecionam em cidades próximas a comunidades quilombolas com a perspectiva de professores/as que tiveram contato com conteúdos sobre a diversidade cultural e as relações étnico-raciais.

A escolha do método de entrevista semiestruturada e da abordagem qualitativa deve-se ao fato da investigação propor analisar aspectos subjetivos referentes às representações de professores/as. Bardin (2011, p.34) sugere que "a análise de conteúdo pode ser uma análise dos 'significados' [...]", sendo utilizada na apuração de dados com conteúdos subjetivos. Para analisar a visão de profissionais do magistério da educação básica sobre as religiões afro-brasileiras, o estudo tomou como referência o conceito de representação a partir da perspectiva dos estudos culturais. 


\section{CULTURA, SISTEMAS SIMBÓLICOS E REPRESENTAÇÃO}

A cultura pode ser entendida como um sistema de significação partilhado pelo grupo social. O sistema simbólico representa a realidade. No mundo simbólico encontram-se crenças, valores e ideologias que compõem o sistema cultural de determinado grupo. Pessoas ou grupos sociais podem ser representados de forma parcial, ou simplificada pelo sistema de símbolos. A invisibilidade e a construção de estereótipos sobre valores culturais de grupos marginalizados, nos livros didáticos e no cotidiano da escola, por exemplo, têm como efeito práticas de discriminação e menosprezo em decorrência da formação de uma visão distorcida, ou simplificada da pessoa estigmatizada.

Pesquisas no campo da educação evidenciam a aplicabilidade do conceito de representações para a análise de aspectos subjetivos associados à visão dos indivíduos sobre a realidade. "Ligada a formações culturais e saberes de determinados grupos, a representação social possui uma dimensão simbólica e significante relacionada a contextos locais específicos" (Carvalho, 2017, p.759-760). A representação está associada a estruturas e sistemas simbólicos que envolvem práticas discursivas e significados atribuídos a grupos sociais, a indivíduos, ou a manifestações culturais 54 e religiosas.

As representações podem ser constituídas de maneira estereotipada, produzindo estigmas em relação a pessoas e determinados grupos sociais. No Brasil, representações estereotipadas são associadas às culturas afro-brasileiras e indígenas. Tal aspecto pode ser observado tanto nos livros didáticos quanto no cotidiano da escola. "Em relação à matriz africana, na maioria dos livros didáticos que conhecemos, o ensino sobre a África é geralmente ausente ou é apresentado de modo distorcido ou de forma estereotipada" (Munanga; Gomes, 2006, p.18).

Dessa maneira, diferentemente de países como os Estados Unidos e a África do Sul, que tinham formas de segregação racial no sistema legislativo, na sociedade brasileira o racismo se evidencia no sistema simbólico, reforçado pela invisibilidade e a construção de estereótipos sobre as culturas africanas, afro-brasileiras e indígenas. No âmbito da educação brasileira, "a discriminação racial se faz presente como fator de seletividade na instituição escolar e o silêncio é um dos rituais pedagógicos por meio do qual ela se expressa" (Gomes, 2012, p.105). A concepção do silêncio, entendida como ritual pedagógico no espaço escolar no tocante às 
formas de discriminação racial, bem como com relação às culturas africanas e afro-brasileiras, foi demonstrada pelas pesquisas realizadas por Gonçalves (1985; 1987) na educação básica do Brasil, na década de 1980.

Assim, na sociedade brasileira, o racismo possui especificidades associadas ao mito da democracia racial, baseado na suposta convivência harmônica entre diferentes grupos étnicos. De acordo com Schwarcz (2013, p.78), no Brasil se formou "um racismo sem cara, que se esconde por trás de uma suposta garantia da universalidade das leis e que lança para o terreno do privado o jogo da discriminação", afirmando-se "de forma privada", dependendo, no entanto, "da esfera pública para sua explicitação [...]".

Representações estereotipadas e formas de discriminação racial estão associadas a práticas de significação que constituem os sistemas simbólicos. No tocante ao conceito de representação, Hall (2010) se refere à construção de estereótipos no sistema simbólico. Modos de representação de um determinado grupo social podem ser concebidos como símbolos de um tabu, tendo como efeito a construção de estigmas, a invisibilidade e a exclusão do grupo. As diferenças podem ser desconsideradas pelo sistema simbólico, como é o caso da omissão de diferenças de "raça", classe e gênero na afirmação da identidade. Os processos de constituição de identidades "funcionam por meio da exclusão, por meio da construção discursiva de um exterior constitutivo e da produção de sujeitos [...] marginalizados, aparentemente fora do campo simbólico [...]" (Hall, 2000, p.129).

Outro aspecto relevante em relação aos sistemas simbólicos é que as representações podem ocorrer mediante processos de marcação das diferenças. "Essa marcação da diferença ocorre tanto por meio de sistemas simbólicos de representação quanto por meio de formas de exclusão social" (Woodward, 2000, p.39). Sistemas classificatórios estabelecem diferenças simbólicas e sociais correspondentes a modos de identificação cultural e manifestações religiosas. Nos processos de formação dos sistemas simbólicos, "a diferença pode ser construída negativamente — por meio da exclusão ou da marginalização daquelas pessoas que são definidas como 'outros' [...]" (Woodward, 2000, p.50), ou como indivíduos indesejados pela maioria do grupo. Esse modo de construção da identidade é observado no tocante às religiões afro-brasileiras.

Nilma Gomes (2012) apresenta uma contribuição importante para uma análise acerca das representações de professores/as sobre as culturas africanas e afro-brasileiras. Referindo-se à promulgação da Lei 10.639/2003, Gomes (2012, p.106) ressalta 
que o paradigma epistemológico se caracteriza como "um campo de tensões e de relações de poder que nos leva a questionar as concepções, representações e estereótipos sobre a África, os africanos, os negros brasileiros [...]". É importante verificar o potencial de programas de formação continuada de professores/as da educação básica "no processo de ruptura epistemológica e cultural na educação brasileira" para uma concepção multicultural da sociedade e "a superação da perspectiva eurocêntrica de conhecimento e do mundo [...]" (Gomes, 2012, p.106-107).

Na pesquisa, propomos analisar os sentidos, significados e representações sobre as religiões afro-brasileiras e as relações étnico-raciais a partir da visão de professores/ as da educação básica da rede pública de ensino, considerando os seus discursos e as suas narrativas sobre a temática. O conceito de representações, associado aos sentidos e significados atribuídos a um modo específico de construção da realidade, possibilita uma compreensão mais abrangente da visão de profissionais do magistério sobre as religiões afro-brasileiras no âmbito da escola.

\section{AS RELIGIÕES AFRO-BRASILEIRAS}

A cultura de um povo está intrinsecamente ligada à sua constituição e às suas raízes. As religiões de matriz africana cumprem nesse sentido um papel significativo no Brasil, visto que a crença nas suas divindades, bem como outros elementos culturais, atuou como um artifício unificador dos vários povos africanos que aqui vieram. Munanga $(2012$, p.19) destaca a relevância da recuperação da identidade afrodescendente a partir da "aceitação dos atributos físicos de sua negritude antes de atingir os atributos culturais, mentais, intelectuais, morais e psicológicos [...]".

Caracterizadas, de modo geral, por suas práticas religiosas, hoje existentes no país, as religiões de matriz africana, ou religiões afro-brasileiras, têm ligação, próxima ou remota, com os cultos trazidos por povos africanos introduzidos como escravos no Brasil. Esses cultos recebem nomes diferentes segundo as várias regiões do país, como por exemplo: tambor de mina, no Maranhão; batuque, no Pará; catimbó, em grande parte da região Nordeste; pajelança, no Norte; xangô, em Pernambuco; candomblé, na Bahia; macumba, no Rio de janeiro e São Paulo; e umbanda, existente em quase todo o território brasileiro. 
"No que diz respeito à religiosidade, os africanos legaram ao Brasil algumas de suas religiões populares, tais como o Candomblé, Umbanda e Macumba, que fazem parte do patrimônio religioso brasileiro" (Munanga; Gomes, 2006, p.22). No Rio Grande do Norte, entre as muitas denominações dessas religiões estão o candomblé, a jurema, a umbanda e o xangô (Silva, 2011, p. 27).

Religião formada no Brasil com a diáspora dos povos africanos, o candomblé caracteriza-se pela resignificação de rituais religiosos das etnias nagôs e jejes. “Desde o princípio, o candomblé combinou, no novo ambiente do Brasil, elementos culturais impostos aos escravos com o contato entre grupos étnicos cujo número era sempre renovado pelo tráfico" (Schwarcz; Starling, 2015, p.105). Nas terras colonizadas pela coroa portuguesa nas Américas, as religiões de matriz africana de diferentes grupos étnicos, trazidos da África durante a diáspora do Atlântico Sul, foram reconstruídas e associadas a santos católicos, rituais e tradições indígenas.

Schwarcz e Starling (2015, p.86) sugerem que "o candomblé é uma religião derivada do animismo africano, de origem totêmica e familiar, em que se cultuam orixás, os quais no Brasil foram logo vinculados aos santos católicos [...]" para a proteção e a continuidade de rituais e práticas religiosas africanas. "Na África, ao que tudo indica, cada nação celebrava apenas um orixá: portanto, a junção dos cultos foi uma especificidade da leitura brasileira feita por nativos entrados na colônia como escravos" (Schwarcz; Starling, 2015, p.86). Separados na chegada aos portos para evitar motins e rebeliões, diversificados grupos étnicos africanos conviveram nas embarcações, senzalas, cidades e quilombos no Brasil, durante o período colonial.

As trajetórias de construção da legitimidade das religiões afro-brasileiras, sobretudo o candomblé e a umbanda, estão vinculadas à trajetória de legitimação da cultura afrodescendente no país e da própria cultura brasileira. Tal processo de construção de legitimidade permite compreendermos como essas religiões passam a ser concebidas como uma expressão de matriz africana, uma herança, manipulada ao longo de todo o século XX.

A Lei 11.645/2008, que tornou obrigatória a educação étnico-racial nas escolas, através do ensino da história e da cultura africana e afro-brasileira e também indígena, vai dialogar diretamente com essas trajetórias. Formada a partir da escravização e marcada pela ausência de políticas governamentais em favor de direitos das populações afrodescendentes e indígenas, o alcance da justiça social no Brasil requer a execução de programas e ações que promovam a igualdade racial. Neste sentido, a escola caracteriza-se como uma instituição que pode pos- 
sibilitar a formação de uma consciência cidadã, sendo importante a implantação de estratégias de combate à discriminação racial, conhecimento e valorização das culturas afro-brasileiras e indígenas.

De acordo com a Lei 11.645/2008, os conteúdos referentes à história e cultura afro-brasileira e dos povos indígenas brasileiros devem ser ministrados no âmbito de todo o currículo escolar, em especial nas áreas de educação artística e de literatura e história. Todavia, apesar de já existirem desde o início da primeira década do século XXI, as leis que tratam da inclusão de conteúdos sobre as culturas africanas e afro-brasileiras incorporadas à LDB ainda não foram integralmente assimiladas no sistema educacional.

Infelizmente, existe uma dificuldade histórica de lidar com a temática étnico-racial no Brasil, principalmente devido ao desconhecimento e desvalorização das culturas indígenas e afro-brasileiras, aliada à formação de uma concepção de nação homogênea, sem diferenças raciais. Na educação brasileira, a ausência de um trabalho sistemático sobre a diversidade cultural no planejamento escolar tem impedido a promoção de relações interpessoais respeitáveis e igualitárias entre os agentes sociais que integram o cotidiano da escola.

Esse problema tem se mostrado comum no ambiente escolar. Em razão de perspectivas deturpadas por motivos religiosos, repertórios das culturas populares ligados às religiões afro-brasileiras têm encontrado resistências de pais, profissionais e até alunos/as. O mito da democracia racial ainda predomina em muitos discursos, além do preconceito institucionalizado e da intolerância religiosa, criando entraves e dificuldades para o conhecimento sobre as religiões de matriz africana e o respeito à alteridade.

Considerando que parte-se, no presente estudo, de uma pesquisa qualitativa, a qual não pode ser generalizada, os resultados da investigação tornaram mais evidente a importância da formação continuada de educadores/as para o início de uma ruptura epistemológica e da mudança dessa realidade. Tal aspecto fica claro quando são comparados os discursos dos/as professores/as entrevistados, os quais evidenciam diferenças de percepção e representação sobre as religiões afro-brasileiras.

Sem dúvida, o ensino de história e cultura africana e afro-brasileira impõe um desafio à escola enquanto instituição e aos/às professores/as como sujeitos que se veem diante de um processo que lhes obriga a repensar a visão de mundo a partir da qual construíram suas práticas. A escola constitui um espaço importante para a implantação de estratégias de combate à discriminação racial no Brasil. Daí a 
relevância do conhecimento sobre as matrizes africanas das religiões afro-brasileiras para valorização das identidades afrodescendentes e promoção da igualdade racial no espaço escolar.

\section{REPRESENTAÇÕES DE PROFISSIONAIS DA EDUCAÇÃO BÁSICA SOBRE AS RELIGIÕES DE MATRIZ AFRICANA}

Para a análise dos discursos dos/as professores/as entrevistados/as utilizou-se a sigla PCQ para designar profissionais da educação básica que lecionam em cidades próximas a comunidades quilombolas e a sigla PEAD para referir-se a docentes que realizaram formação continuada na modalidade de EAD sobre a diversidade cultural e as relações étnico-raciais.

Entre os/as entrevistados/as que não realizaram o curso de formação continuada ofertado pela UFRN e lecionam em municípios próximos a Comunidades Quilombolas, a questão sobre as religiões de matriz africana causou maior estranheza, indiferença e repulsão em alguns casos. O grupo dos/as professores/as que realizaram o curso de formação continuada oferecido pela UFRN na modalidade de EAD mostrou conhecimento sobre as religiões de matriz africana, destacando a importância de abordar as manifestações religiosas das culturas afro-brasileiras na sala de aula, bem como o respeito à diversidade cultural.

Para sistematização do estudo, a análise das representações dos/as professores/ as entrevistados/as foi subdividida em duas partes. Primeiramente será tratada a perspectiva dos/as docentes que lecionam em cidades próximas a comunidades quilombolas que não realizaram o curso de formação continuada ofertado pela UFRN. Em seguida são analisadas as representações dos/as professores/as que tiveram acesso a conteúdos sobre as culturas africanas e afro-brasileiras por intermédio do curso oferecido pela UFRN.

É importante frisar que, assim como outros cursos da modalidade de EAD, o curso de Educação para as Relações Étnico-Raciais da UFRN teve um índice de evasão elevado, ultrapassando o percentual de 70\%. Apesar do alto índice de evasão, que merece mais pesquisas específicas sobre o problema, o referido curso apresenta resultados positivos no tocante ao aprendizado de conteúdos sobre as culturas africanas e afro-brasileiras, a diversidade cultural e as relações étnico-raciais. 


\title{
4.1 Professores/as que não realizaram o curso da UFRN e lecionam em cidades próximas a comunidades quilombolas
}

Entre os quinze professores/as entrevistados/as que fizeram parte do grupo que leciona em escolas próximas a comunidades quilombolas nas cidades de Assu (RN), Ipanguaçu (RN), Patu (RN) e Portalegre (RN), poucos quiseram dialogar sobre as religiões de matriz africana, ou expressar uma opinião. Os discursos dos/as docentes revelaram a falta de conhecimento e o desinteresse com relação ao assunto. Tal aspecto ficou evidente em algumas falas, sendo inclusive admitida por alguns/ mas entrevistados/as:

\begin{abstract}
Candomblé é mais a cultura africana... eu não conheço muito candomblé... ai pra falar sobre o que eu não conheço é difícil... a questão sobre a religião indigena... ou africana... eu nunca tive essa curiosidade de ir a fundo no que seria o candomblé (PCQ6).

Vixe, assim, não conheço bem, só mesmo de ouvir falar... assim nunca tive nem curiosidade de ler a respeito, é algo muito diferente da cultura que eu tô acostumada a vivenciar no dia a dia, mas assim nada... de negativo até porque eu não conheço... Só teria condições de responder se de fato eu conhecesse (PCQ11).
\end{abstract}

Além do desconhecimento e desinteresse com relação às religiões de matriz africana, uma das professoras entrevistadas, que leciona ensino religioso, mencionou que "a escola não tem aquele material e o professor tem que correr atrás. Então eu vou na internet e pego as maiores religiões do mundo... aí das maiores a gente vai falando um pouco de cada..." (PCQ6). A partir dos discursos citados, as representações dos/as docentes entrevistados/as podem ser associadas ao ritual pedagógico do silenciamento no tocante às culturas africanas e afro-brasileiras (Gomes, 2012; Gonçalves, 1985;1987). Os discursos ainda evidenciam a percepção que as religiões de matriz africana possuem menos valor do que "as maiores religiões do mundo".

Outro professor afirmou não ter opinião formada sobre a questão, mas acabou expressando representações preconceituosas pela forma a que se referiu ao assunto: "Olhe... assim, eu não... não faço, não tenho a menor opinião sobre isso" (PCQ7). Novamente, a perspectiva de mais dos/as professores/as entrevistados/as se aproxima da concepção do silêncio como ritual pedagógico quando o assunto abordado diz respeito às religiões de matriz africana. Nos discursos da maioria dos/ as professores/as que lecionam em municípios próximos a comunidades quilombolas observa-se a omissão e o silenciamento com relação às manifestações religiosas afro-brasileiras. 
Contudo, o preconceito, velado ou evidente, e a maneira pejorativa com que são tratadas essas religiões, sejam elas quais forem, candomblé, umbanda etc., está além dos limites do conhecer do/a professor/a no espaço escolar, ou pelo menos, do que este/a acredita que conhece. Tal aspecto pode ser notado na perspectiva de uma professora, quando compara candomblé e umbanda:

Eu acho que é uma forma de expressão normal... agora, é claro que existe, né... o verdadeiro candomblé que nós não conhecemos, existe os terreiros de macumba que é outra história, que é essa confusão... eu acho que há discriminação e... até há ignorância por causa desse conflito... Uma coisa é o Candomblé com todos os seus ritos e com a sua beleza e outra coisa é os terreiros de macumba que o povo se veste feito um bocado de doido e começa aquela batucada que é... eu acho que o que precisa fazer é esclarecer. Se o candomblé fosse realmente trabalhado como ele é, as pessoas perderiam até o medo, acho que é desmistificar, na hora que desmistificar... (PCQ2).

A partir dos discursos dos/as professores/as entrevistados/as, é possível observar o modo como o indivíduo constrói representações sobre o mundo em que vive. Marcar a diferença, ou o diferente, ocorre tanto por meio de sistemas simbólicos de representação quanto por meio de formas de exclusão social, onde a diferença pode ser construída negativamente, como assinalou Woodward (2000).

Ser visto como diferente - para não falar demoníaco — ou excluído dos parâmetros do que seria uma religião, para as religiões de matriz africana no Brasil é algo corriqueiro. Assim, a fala da professora busca diferenciar o candomblé da macumba, questionando a legitimidade da macumba como expressão religiosa de matriz africana. Os terreiros de macumba são vistos pela professora como uma "confusão" e a discriminação ocorria devido à falta de conhecimento sobre o candomblé que seria confundido com a macumba.

Outros discursos reforçaram a ideia de demonização de religiões como o candomblé. Uma docente citou uma atividade desenvolvida na escola que foi considerada catastrófica devido exatamente a uma representação estereotipada dos rituais religiosos de matriz africana.

Há dez anos atrás né, quando eu era mais ousada... hoje eu tô... terminando a minha vida profissional. Há dez anos atrás eu trabalhei... com os meus alunos as religiões e... então, teve uma menina... teve duas meninas que apresentaram o candomblé... assim, ela não me disse que ia fazer aquilo... ela inventou que tinha recebido um espírito... essa menina fez tanta da macacada que quando terminou eu fui chamar a atenção, ai ela foi dizer: "- Vocês desculpem, eu fiz brincando". Eu disse: - mulher isso não é brincadeira não, você ficou de uma forma que ninguém Ihe controlava... você fez coisas que eu nunca imaginei que você fosse capaz de fazer... então depois dessa... eu 
acabei minhas atividades, parou aí. Essa menina virava os olhos, essa menina caía, essa menina babava, essa menina gritava... e era uma história de quem é você, quem é você. Fiquei louquinha (PCQ3).

No discurso da professora observa-se a construção de estereótipos e a exclusão da alteridade (Hall, 2010). O ritual religioso de matriz africana é apresentado de forma caricaturada e estereotipada pela aluna na atividade proposta pela professora. A experiência levou a professora a não propor mais atividades relacionadas com as religiões de matriz africana. Aspectos que caracterizam rituais e práticas em religiões como o candomblé e a umbanda são representados de forma estereotipada. Percebe-se uma representação estereotipada por parte da aluna em uma atividade escolar que tratou do candomblé. A experiência conduz a professora ao ritual pedagógico do silêncio quando a temática se refere às manifestações religiosas afro-brasileiras (Gomes, 2012; Gonçalves, 1985;1987).

Em outros discursos é possível perceber o preconceito, não assumido, mas sob a forma de negação dessas religiões por alguém que pertence a outro segmento religioso. Nesse caso, nem mesmo uma formação na área resolveu o problema:

... a gente fez um curso agora recente com os professores aqui sobre educação das comunidades quilombolas... esse tema bastante tratado inclusive, o tema da religião... a minha fala vai parecer mais uma vez preconceituosa, mas não é preconceito. Eu não vejo o candomblé como uma religião... eu sou evangélico, eu tenho essa educação evangélica, eu quero respeitar quem faz de tal, mas eu não, eu confesso a você que correndo o risco de parecer preconceituoso, e digo não sou, tudo bem, mas eu não entraria em qualquer lugar que tivesse candomblé nem aceitaria qualquer reunião... se fosse feita na minha casa, por exemplo, mas defendo a liberdade de que se querem fazer façam (PCQ14).

Um/a dos/as entrevistados/as destacou a relevância do conhecimento sobre as culturas para superação dos preconceitos, mas fez questão de deixar claro que não aceitava o candomblé, nem o considerava como uma religião, como pode ser observado em seu relato. O discurso do professor pode ser associado ao que Schwarcz (2013, p.78) concebe como "um racismo sem cara", afirmado "de forma privada", mas externado na "esfera pública".

Em seu discurso, o professor externa a preocupação de não ser visto como preconceituoso, reforçando a ideia da não existência do racismo na sociedade brasileira. Ao comentar que trabalhou o tema da diversidade cultural em atividades na sala de aula, o professor volta a expressar preocupação em não ser considerado preconceituoso, mencionando novamente o candomblé. 
Eu misturei diversidade cultural com diversidade étnica embora estão bem juntas mesmo. É justamente pra que se possa... até mesmo por uma questão histórica trabalhar diversidade cultural você trabalhar a raiz de cada vertente da cultura, que povo trouxe o conhecimento histórico que provavelmente deve levar respeito às várias vertentes culturais... aí você pode até tá pensando: e não respeita o candomblé... eu respeito eu só não quero, não sou obrigado a aceitar. Como é que eu iria na minha casa, ou a participar? Do mesmo jeito que eu não gosto de sertanejo, mas respeito quem gosta... tudo bem (PCQ14).

Para não generalizar a questão, a opinião de outro professor, também evangélico, chamou a atenção. Apresentando um posicionamento diferente dos/as outros/as docentes entrevistados/as, o professor mostrou que uma boa formação e o acesso ao conhecimento por meio das tecnologias digitais surtem efeitos positivos para a desconstrução de estereótipos, preconceitos e formas de discriminação:

Hoje eu tenho uma concepção mais ampla né, que quando a gente é evangélico novo, convertido... a gente foca muito numa visão... a gente acaba achando que tudo é do demônio, um exemplo, mas hoje eu já terminei... um curso que falava... exatamente sobre isso e eu vendo, eu tô terminando teologia também e eu vi que um pouco por exemplo da igreja, que eu sou da linhagem pentecostal, então, um pouco do pentecostalismo ele, eles já pegaram um pouco... daquela questão da África que você vê muitos movimentos pentecostais se parecem bastante com o que acontece por exemplo na reunião africana... um exemplo né, então eu acho assim que, a minha visão é essa, eu acho que cada um deve respeitar... você deve respeitar o que você crê defender o que você crê é... mas respeitando a decisão do outro (PCQ4).

Entre os/as docentes entrevistados/as, o professor foi um dos únicos a abordar mais o assunto, referindo-se a um curso que havia feito na internet associado ao tema das religiões de matriz africana. Em sua fala, o professor salienta o processo de demonização de manifestações religiosas. Externando a sua crença religiosa, ao afirmar ser evangélico, o entrevistado defende a importância do respeito a outras crenças religiosas. Por fim, o docente ainda ressaltou a relevância do respeito de escolha no tocante à religião.

Eu vejo que tanto ainda uma briga muito grande entre as igrejas e tal, por exemplo, ah porque a minha igreja é do cão e fica o tempo todo aquela... eu acho que não é por aí o caminho... o Brasil... é um país laico... você é evangélico, viva o seu evangelho... faça aquilo que você aprendeu na biblia e tal e respeito à decisão do outro... se o outro quer seguir o mesmo caminho, seja bem vindo, mas se não quer, isso não impede de viver em comunhão com a outra pessoa (PCQ4).

Outras respostas, apesar de serem superficiais, também denotaram concepções de consciência sobre o assunto, bem como manifestação de respeito sobre a religião do outro: "[...] não tem o conhecimento real... aí fica com medo" (PCQ3). Para 
justificar o respeito à diversidade religiosa, o/a professor/a enfatizou a laicidade do Estado. "Eu acho que tem que ser respeitado por todo e qualquer manifestação religiosa... até porque o país já que tem uma constituição que se diz laica, todas as crenças, todos os cultos devem ser respeitados" (PCQ12).

Na análise das entrevistas observou-se que a maioria dos/as professores/as, que não realizaram o curso de formação continuada ofertado pela UFRN e que lecionam em escolas próximas a comunidades quilombolas, não demonstraram muito interesse em falar sobre as religiões de matriz africana. No geral, as falas dos/as professores/ as podem ser relacionadas com o que Gonçalves $(1985 ; 1987)$ denominou de ritual pedagógico do silêncio (Gomes, 2012).

Com a exceção de um professor que comentou ter feito um curso sobre as religiões de matriz africana na internet, a maioria dos/as entrevistados/as demonstrou desconhecimento e desinteresse pelo assunto. Ressalta-se que os/as docentes lecionam em escolas que atendem crianças oriundas de comunidades quilombolas. Além da invisibilidade das culturas africanas e afro-brasileiras no que diz respeito às manifestações religiosas, os/as professores/as não levam em consideração as Leis 10639/2003 e 11.645/2008, bem como as Diretrizes Curriculares Nacionais para

64 Educação das Relações Étnico-Raciais. Apesar do pouco conhecimento acerca de religiões afro-brasileiras, como o candomblé e a umbanda, alguns/mas entrevistados/as ressaltaram a importância do respeito à liberdade de escolha das pessoas.

\subsection{Representações de professores/as que realizaram formação continuada sobre educação para as relações étnico-raciais}

Diferentemente de atitudes de estranheza e repulsão, nos discursos de docentes que realizaram o curso de EAD ofertado pela UFRN destacam-se a importância do conhecimento sobre a diversidade cultural e o respeito às alteridades. As representações de profissionais do magistério da educação básica que tiveram contato com conteúdos sobre as culturas africanas e afro-brasileiras por meio de cursos de formação continuada mostram a relevância do assunto para a educação étnicoracial na escola. Um/a dos/as professores/as ressaltou a pertinência do curso para o seu conhecimento sobre o tema:

Até então eu não conhecia, não conhecia muito bem... foi no curso mesmo que eu fui ter... o primeiro contato... com a religião. É diferente... é completamente diferente da religião que eu sigo. Sou católica, mas... respeito. É interessante a gente conhecer novas religiões (PEAD9). 
Outro/a professor/a enfatizou a origem africana do candomblé, defendendo o respeito à diversidade cultural.

Eu participei do curso de extensão da cultura afro e achei muito interessante o que fala a respeito do candomblé. O candomblé é de origem africana e ele, pra nós brasileiros, muita gente confunde o candomblé como macumba, coisa do diabo, quer dizer, mistifica... muita gente acha que essa religião, esse culto que eles têm no candomblé é uma coisa maligna, o que no fundo no fundo não é. É uma cultura deles. É uma cultura da África, a cultura desse povo. É um ato deles se expressarem espiritualmente, porque eles têm uma espiritualidade muito aguçada, esse pessoal da África. Eles não "é" aquele povo, por exemplo, de outro país, vamos supor, do Oriente, não. A cultura deles, do candomblé, é de exteriorizar a sua fé na divindade (PEAD12).

O professor entrevistado mostra que foram construídos estereótipos em relação ao candomblé, enfatizando o processo de mistificação da religião. Em sua fala podese observar a relação com as culturas africanas. Apesar de relacionar a macumba com "coisa do diabo", a fala do professor evidencia um processo incipiente de "ruptura epistemológica e cultural" (Gomes, 2012, p.106), resultante de cursos de formação continuada voltados para o tema das culturas africanas e afro-brasileiras e a educação para as relações étnico-raciais.

Em outro relato, uma docente referiu-se ao impacto causado quando se fala de religiões afro-brasileiras na sala de aula, ressaltando por isso a importância de se trabalhar sistematicamente com essa temática:

Assusta... Quando se fala... fala assim, é "professora, é, aquele que fica rodando?" Na sala de aula há um ... impacto... tem que mostrar... Porque é só assim, a criança ela vai tirar esse impacto que ela sente. De sociedade, do terreiro... Tanto é que uma criança que os pais são do candomblé, eles não dizem... Já ficam dizendo, "ah, filhinho de...", como é? "Não sei o que do terreiro", "Eu vi você viu, eu soube que seu pai é catimbó Jerusa", usam muito essa palavra (PEAD1).

Diferentemente da professora que não quis trabalhar mais com a temática por causa de formas estereotipadas de representação, a entrevistada enfatizou a necessidade de desconstruir preconceitos sobre o terreiro, o candomblé, ou o catimbó. É importante frisar, a partir do discurso mencionado acima, o receio dos pais de que a criança declare para colegas na escola a sua crença religiosa. Tal receio pode ser visto como um efeito do silêncio e da invisibilidade das culturas africanas e afro-brasileiras no espaço escolar (Gonçalves, 1985; 1987). Trata-se de uma situação totalmente adversa se comparada com outras religiões, como a católica ou a evangélica. Ocorre o mesmo fenômeno com relação a orientações sexuais que não se encaixam no padrão heterossexual. 
Uma professora mencionou a relevância dos materiais didáticos do curso para a construção de uma visão mais abrangente sobre as religiões de matriz africana. Segundo a professora:

Na questão como propriamente no material lá do curso que a gente trabalhou tinha muita a questão da religião, onde a gente viu muito a questão do candomblé, onde nós tivemos a oportunidade de ver uns vídeos lá nas aulas práticas, nas aulas presenciais que nós tivemos no curso veio um antropólogo nessa questão da religião (PEAD 9).

Observa-se a importância de cursos de formação continuada na modalidade de EAD, mesmo considerando problemas como os altos índices de evasão. Professores/as que realizaram o curso ofertado pela UFRN comentaram que passaram a trabalhar com a temática das religiões de matriz africana na sala de aula.

Uma professora afirmou que "fez um trabalho sobre isso e entrou a religião", contudo, sentiu "um pouco de impacto", ressaltando que é necessário "mostrar porque só assim a criança vai tirar esse impacto que ela sente [...] do terreiro" (PEAD1). Na fala da professora se evidencia a naturalidade com que passou a ser tratado o terreiro como espaço de rituais religiosos afro-brasileiros. Outro aspecto interessante mencionado pela professora diz respeito a uma preocupação dos pais que orientam as crianças a não revelarem a sua religião quando esta tem uma matriz africana. Segundo a professora entrevistada, "uma criança que os pais são do candomblé, eles não dizem... eles não querem dizer. Eles mesmos têm um próprio preconceito. A criança quando chega em sala já ficam dizendo... eu vi você viu, eu soube que seu pai é catimbó Jerusa" (PEAD 1).

Assim, a construção do preconceito permeia o meio familiar, os meios de comunicação de massa e a instituição escolar. As crianças chegam na escola com visões preconceituosas que reforçam estereótipos sobre as religiões de matriz africana. Destaca-se que o curso de formação continuada da UFRN não propiciou, nesse caso específico, uma visão sobre a interiorização do preconceito em pessoas que sofrem com mecanismos de estigmatização e formas de discriminação racial. No entanto, destaca-se que a professora mostra interesse em desconstruir estereótipos e preconceitos com relação às religiões afro-brasileiras no cotidiano da escola.

Em outra fala, uma professora comentou que fez uma atividade "com os meninos e que foi discutir a religião, ai a gente aprendeu o quanto nós temos da religião afro dentro da nossa cultura, mas que isso é um pouco deixado pra trás" (PEAD3). A professora ainda mencionou um trabalho que um aluno protestante apresentou sobre o candomblé. 
Então, o ano passado eu trabalhei com os meninos exatamente isso, e o menino que fez uma apresentação... ele é até de outra, outra religião... ele é protestante e ele que fez a apresentação falando do candomblé, aí ele explicou bem direitinho, porque eu deixei bem claro, né? Que a gente tem que respeitar a religião do outro para aprender a respeitar o outro. E ele por ser dessa, dessa religião, ele fez uma apresentação muito boa, explicou para os colegas, né? Eu pra mim foi uma alegria, que ele ser de outra, outra religião, que a gente sabe que, assim... É muito, muito... Como é que se diz? Conservadora, né? A questão da religião protestante. E ele na escola... ele fez o trabalho, mostrou para os colegas e... foi fantástico assim, e ouvindo dele... Ele até outro dia tava agradecendo, porque... Por ter estudado esse lado também (PEAD3).

A iniciativa de trabalhar conteúdos que se referem às religiões de matriz africana, como o candomblé, mostram que a desconstrução dos preconceitos perpassa pelo conhecimento dos elementos que compõem a cultura da sociedade brasileira. Antes da Lei 10.639/2003, as culturas africanas e afro-brasileiras não eram trabalhadas na escola. Os/as alunos/as compreendiam a formação da sociedade brasileira a partir de uma visão eurocêntrica e colonizadora. As representações dos/as professores/ as que realizaram a formação continuada pela UFRN evidenciam uma "ruptura epistemológica e cultural" incipiente no âmbito da educação brasileira (Gomes, 2012, p.106).

Em duas falas, vemos que os/as professores/as enfatizam a necessidade do conhecimento sobre as culturas africanas e afro-brasileiras para respeito à alteridade:

Eu percebo que sim, que a gente tinha que aprender... Nós precisamos ainda trabalhar mais com os nossos colegas professores, pra essa coisa ficar mais ampla, pra chegar no aluno... (PEAD3).

[...] a gente sempre trabalha de uma forma respeitosa... Se conversa, se comenta - até porque passa na televisão - mas são poucos. Eu vejo que essa questão religiosa não é uma questão que afeta muito as crianças porque eu vejo que ela é pouco discutida e pouco trabalhada, até por isso, por termos praticamente duas religiões. Quando é o período a gente trabalha e mostra. No projeto a gente fez uma tenda para jogar os búzios. Tem um site na internet que você joga os búzios e diz. A gente fez uma tenda na sala de aula, bem grande. Os pais ficaram emocionados. Ali praticamente foi o primeiro contato, mas eles não repudiaram... de maneira nenhuma. Acharam aquilo interessante. É só mesmo que não se tem conhecimento, até por ser um tema discutido muito pouco... (PEAD11).

Apesar do desenvolvimento de atividades na sala de aula para abordar as religiões afro-brasileiras, percebe-se na fala de PEAD11 que o predomínio das religiões católica e protestante justificaria não tratar de outras religiões no espaço escolar. Neste caso, o curso de formação continuada da UFRN não surtiu efeito no sentido 
de construir uma percepção da relevância das religiões de matriz africana para a formação da cultura brasileira. Mesmo tendo realizado o curso de formação continuada, a professora comentou que "o conhecimento é pouco em relação a essa religião" (PEAD11).

Outra professora disse que "sobre a religião... não existe religião certa e nem existe religião errada. A religião certa é aquela que faz bem" (PEAD 15). Apesar de não aprofundar a questão especificamente sobre o candomblé, a umbanda e outras religiões de matriz africana, a professora apresenta uma visão relativista em relação à religiosidade.

Porém, ainda existem aqueles/as que não adquiriram um conhecimento mínimo, mas assumem isso, como se evidencia no discurso a seguir: "Não. Eu sinceramente explorei muito pouco. Assisti alguns vídeos, mas não ficou muito conhecimento para o meu lado não" (PEAD8).

No mais, duas respostas resumem os modos de representação dos/as professores/as com relação às religiões afro-brasileiras, onde o respeito, a consciência do direito ou da liberdade de escolha, e mesmo a admiração pela religião do outro são expressas. Um/a professor/a inclusive assume já ter feito parte de um terreiro:

É uma religião tanto como as outras. Eu vejo que todos nós temos o direito de optar por uma religião. Eu tenho respeito tanto por uma como a outra. Essas religiões, que muitos não respeitam, é porque eles não têm o respeito pelo próximo. Eles querem saber o "eu". Mas é a fé deles, eles estão com aquela fé, eles têm aqueles princípios. Eu tenho meu princípio, você tem o seu princípio, mas é uma religião como outras. Eu não vou afirmar quantas religiões existem no mundo, são várias, com o mesmo objetivo: de adorar só um Deus; todos têm os mesmos objetivos de alcançar a fé, a saúde, o sucesso e a lealdade. Porque eu vou discriminar a religião do candomblé? Eles têm uma forma diferenciada de viver, maravilhosa, uma religião como a minha ou como outra qualquer (PEAD13).

Eu acho que do mesmo modo que acontece com a religião candomblé, a religião budista, como qualquer religião, ali há um Deus, e que você tem que acreditar e atribuir aquilo a Ele como em qualquer outra religião. Eu já fiz parte de terreiros, e eu acho aquilo encantador (PEAD14).

Assim, apesar de problemas nos cursos de EAD (Carvalho, 2014), como os índices elevados de evasão, observa-se o impacto na educação básica dessa modalidade educacional em mudanças no modo como os/as educadores/as compreendem e representam temáticas concernentes às relações étnico-raciais e à diversidade cultural, principalmente no tocante a questões que ainda geram polêmicas, como é o caso das religiões afro-brasileiras. 
Entre os discursos dos/as entrevistados/as merece destaque a importância do respeito à diversidade cultural e religiosa existente no país. Um/a dos/as professores/as entrevistados/as destacou a questão do preconceito em função da cor na escola. O/a professor/a afirmou que gosta "de trabalhar com dinâmicas para observar os que estão sendo rejeitados e na maioria deles a gente vê que é pela questão da cor" (PEAD5).

Como podemos perceber, o curso sobre educação para relações étnico-raciais, realizado pelos/as professores/as, contribuiu de forma significativa para as suas formações, sendo essencial para o processo de "ruptura epistemológica e cultural" (Gomes, 2012). É clara a diferença de concepções entre os dois grupos de professores/as quando indagados sobre temas associados ao preconceito, à discriminação racial, ou à religião afro-brasileira, atentando para o desdobramento da questão no que concerne à escola que os/as docentes lecionam, ou seja, como esse fator exerce influência em sua visão de mundo, nas representações e na prática educacional. A maioria dos/as professores/as que realizou o curso de formação continuada oferecido pela UFRN fez referência a atividades em sala de aula com o tema das religiões afro-brasileiras.

Um/a professor/a mencionou a importância de tratar da diversidade cultural já que a própria escola, situada no município de Felipe Guerra (RN), meio rural da região Oeste do Rio Grande do Norte, apresenta configurações familiares diversificadas, como é o caso de crianças criadas por casais homoafetivos. Para justificar a necessidade de trabalhar a temática na sala de aula, o/a entrevistado/a argumentou que "são crianças criadas por avós, crianças criadas por pais, por mães, por casais do mesmo sexo" (PEAD11), referindo-se a formas diversificadas de configuração familiar.

Apenas duas professoras entrevistadas falaram pouco acerca das religiões de matriz africana. Uma delas reforçou que tinha respeito e disse que "nós não temos muito aqui na nossa região... não tem do candomblé, nem se comenta muito" (PEAD4). Apesar de terem feito o curso de formação continuada da UFRN, as professoras citadas não demonstraram interesse pela temática das religiões afrobrasileiras, aproximando-se mais do ritual pedagógico do silêncio no tocante a temas relacionados com as culturas africanas e afro-brasileiras (Gonçalves, 1985; 1987). 
Desse modo, os discursos dos/as professores/as que realizaram o curso de EAD pela UFRN mostram um conhecimento mais aprofundado sobre os temas das relações étnico-raciais e da diversidade cultural, enfatizando a importância do reconhecimento e do respeito às diferenças.

\section{CONSIDERAÇÕES FINAIS}

A desconstrução de estereótipos e da ideologia do mito da democracia racial, o conhecimento das culturas afro-brasileira e indígena e a inclusão de formas de representação que formem uma visão positiva em relação aos povos indígenas e à população afrodescendente no Brasil são essenciais para a afirmação da identidade e a autoestima desses grupos sociais.

Os resultados da pesquisa podem servir de base para a reformulação e o acréscimo de conteúdos sobre o tema das relações étnico-raciais e a diversidade cultural, contribuindo para preencher lacunas nos programas de formação continuada de professores/as da educação básica. A análise da representação dos/as docentes entrevistados/as evidencia o impacto de políticas educacionais e cursos de formação continuada que tratam de conteúdos voltados para as temáticas das relações étnico-raciais e da diversidade cultural.

As políticas educacionais e os programas de formação continuada de educadores/ as, implantados no Brasil durante a primeira década do século XXI, têm como finalidade proporcionar o conhecimento e a valorização das culturas indígenas, africanas e afro-brasileiras, o reconhecimento da diversidade cultural da sociedade brasileira e a promoção da igualdade racial no espaço escolar. Com a pesquisa foi possível verificar os impactos de tais programas no sentido da inclusão da temática referente às religiões afro-brasileiras na escola.

Nas representações de profissionais do magistério que lecionam em cidades próximas a comunidades quilombolas observam-se estereótipos e visões simplificadas acerca das religiões afro-brasileiras. Ademais, os/as professores/as entrevistados/as mostraram desinteresse pelas religiões afro-brasileiras, refletindo-se na invisibilidade e no silêncio quando o assunto tratado diz respeito a manifestações religiosas de matriz africana. 
Por outro lado, as representações de professores/as que realizaram cursos de formação continuada na modalidade de EAD destacam a importância do conhecimento da diversidade cultural para o respeito à alteridade e a promoção da igualdade racial no espaço escolar. Inclusive os/as profissionais da educação básica que tiveram contato com conteúdos sobre as relações étnico-raciais passaram a trabalhar com a temática das religiões afro-brasileiras nos conteúdos em sala de aula. As representações dos/as professores/as da educação básica que tiveram acesso ao conhecimento acerca das religiões de matriz africana podem ser caracterizadas como formas incipientes de ruptura epistemológica e superação do paradigma eurocêntrico para uma concepção multicultural da sociedade brasileira.

\section{REFERÊNCIAS}

Azevedo, J. M. L. (2000). “O Estado, a política educacional e a regulação do setor da educação no Brasil: uma abordagem histórica". In: Ferreira, N.S. C. e Aguiar, M. A. da S. Gestão da educação. São Paulo: Cortez, pp.17-42.

Bardin, L. (2011). Análise de conteúdo. São Paulo: Edições 70.

Brasil (1996). CONGRESSO NACIONAL. Lei No9.394 de 20 de dezembro de 1996. Estabelece as diretrizes e bases da Educação Nacional. In: Diário Oficial da União de 23 de dezembro de 1996.

Brasil (2001). Plano Nacional de Educação - PNE / Ministério da Educação. Brasília: INEP.

Brasil (2008). Lei No 11.645 de 10 de março de 2008. Inclui no currículo oficial da Rede de Ensino a obrigatoriedade da temática "História e Cultura Afro-Brasileira e Indígena". In: Diário Oficial da União de 10 de março de 2008.

Brasil (2006). Ministério da Educação/ Secretaria da Educação Continuada, Alfabetização e Diversidade. Orientações e Ações para Educação das Relações Étnico-Raciais. Brasilia: SECAD, 2006.

Candau, V. (2008). Multiculturalismo e educação: desafios para a prática pedagógica. In: Multiculturalismo: diferenças culturais e práticas pedagógicas. Antonio Flávio Moreira, Vera Maria Candau (orgs.). 2. Ed. Petrópolis, RJ: Vozes, p.13-37.

Carvalho, G. P (2017). Formação continuada e representações de gênero no espaço escolar. In: Atos de pesquisa em educação. Blumenau, v.12, n.3, p.759-782.

Carvalho, G. P. (2014). Tecnologias Digitais e Educação a Distância. Mossoró, RN: Edições UERN.

Carvalho, G. P.; Silva, E. A. (2015). Justiça Social e Multiculturalismo: As Políticas de Reconhecimento de Identidades Étnico-culturais no Brasil. In: Direitos Fundamentais \& Justiça, Pontífica Universidade Católica do Rio Grande do Sul, Ano 9, n³1. 
Gomes, N. (2012). Relações étnico-raciais, educação e descolonização dos currículos. In: Currículo sem Fronteiras, v.12, n.1, pp. 98-109.

Gonçalves, L. A. O. (1985). O silêncio: um ritual pedagógico a favor da discriminação racial: um estudo acerca da discriminação racial como fator de seletividade na escola pública de primeiro grau: $1^{\circ}$ e $4^{\circ}$ série. Dissertação de mestrado. Programa de Pós-Graduação em Educação, Conhecimento e Inclusão Social da Universidade Federal de Minas Gerais, Belo Horizonte.

Gonçalves, L. A. O. (1987). Reflexão sobre a particularidade cultural na educação das crianças negras. In: Cadernos de Pesquisa, São Paulo, n.63, p.27-30.

Hall, S. (2000). Quem precisa da identidade? In: Identidade e diferença: a perspectiva dos estudos culturais. Tomaz Tadeu da Silva (org.), Stuart Hall, Kathryn Woodward. Petrópolis, RJ: Vozes.

Hall, S. (2010). Sin garantias: Trayectorias y problemáticas en estudios culturales. Colombia: Envión Editores.

Munanga, K.; Gomes, N. (2006). O negro no Brasil de hoje. São Paulo: Global.

Munanga, K. (2012). Negritude: usos e sentidos. $3^{a}$ ed. Belo Horizonte: Autêntica Editora.

Schwarcz, L. (2013). Racismo no Brasil. $2^{a}$ ed. São Paulo: Publifolha.

Schwarcz, L.; Starling, H. M. (2015). Brasil: uma biografia. $2^{a}$ ed. São Paulo: Companhia das Letras.

Silva, A. C. (2005). A desconstrução da discriminação no livro didático. In: Munanga, K. (org.). Superando o Racismo na escola. 2. ed. rev. Brasilia: Ministério da Educação, Secretaria de Educação Continuada, Alfabetização e Diversidade.

Silva, E. A. (2011). Cultos Domésticos, Terreiros e Federação: Legitimidade e práticas religiosas no campo afro-brasileiro de cidades do Rio Grande do Norte. Tese de Doutorado, Universidade Federal de Pernambuco.

Woodward, K. (2000). Identidade e diferença: uma introdução teórica e conceitual. Tomaz Tadeu da Silva (org.), Stuart Hall, Kathryn Woodward. In: Identidade e diferença: a perspectiva dos estudos culturais. Petrópolis, RJ: Vozes, 2000. 